\title{
Impact of aquaculture field school on community fish farming
}

\author{
HIMANSU KUMAR DE, RADHEYSHYAM, GOUR SUNDAR SAHA, LEKHA SAFUI, \\ SURESH CHANDRA, SUBHENDU ADHIKARY, NAGESH KUMAR BARIK AND \\ AMBEDKAR E. EKNATH* \\ ICAR-Central Institute of Freshwater Aquaculture, Kausalyaganga, Bhubaneswar - 751 002, Odisha, India \\ e-mail: bhuthnath@gmail.com
}

\section{ABSTRACT}

\begin{abstract}
Community based aquaculture, a subset of the rural aquaculture, is characterised with low fish production level. Sustainable improvement of productivity levels in such resources has remained a challenge. The study adopted a novel approach of technology transfer through aquaculture field school which involves provision of technical advices and no physical inputs. The article tries to capture its impact on fish production levels and economics of community based aquaculture. The study was conducted during 2009-2012 in Khurda and Puri districts of Odisha by surveying randomly selected farmers of community ponds. Demonstration, need-based skill training, field days, workshops and field visits were organised periodically for fish farmers involved in community based aquaculture management. In order to study the impact of technical inputs, data were collected from 31 randomly selected village community ponds. Farmers provided with technical advices could improve pond management practices significantly $(\mathrm{p}<0.05)$. This included eradication of aquatic weeds, removal of weeds and predatory fishes, enhancing pond productivity, stocking fingerlings and/or yearlings, partially feeding fish with locally available feed. This has resulted in better fish production (@2192 kg ha-1 $\mathrm{yr}^{-1}$ ) than pre-project period (@1081 kg ha $\mathrm{yr}^{-1}$ ). Motivational drive, need based technical advice and follow up action brought behavioral change in fish farmers for higher investment for intensification of pond management. Average expenditure in community based aquaculture rose significantly $(p<0.05)$ from ₹40146 ha $\mathrm{yr}^{-1}$ to ₹87071 ha-1 $\mathrm{yr}^{-1}$. Average net returns from community ponds at the end of the project period increased to ₹95068 $\mathrm{ha}^{-1} \mathrm{yr}^{-1}$ against ₹34057 $\mathrm{ha}^{-1} \mathrm{yr}^{-1}$.
\end{abstract}

Keywords: Aquaculture field school, Community fish farming, Impact, Technical advice

In rural areas, there are diversified freshwater resources with immense potentialities for aquaculture development. Large proportion of freshwater resources available in rural areas falls under community ponds (over $60 \%$ ) vested with community or local level institutions, religious bodies without and/or with resources and local self-government for multiple use and multiple users (Sinha, 1999; Radheyshyam et al., 2011a and Radheyshyam et al., 2013). Out of the total freshwater ponds and tanks ( 2.214 million ha) about $44 \%$ are in use for aquaculture, producing 3.38 million $\mathrm{t}$ of fish at national average productivity of $2.9 \mathrm{t} \mathrm{ha}^{-1} \mathrm{yr}^{-1}$. However, little is known about the rest $56 \%$ of freshwater ponds and tanks (mostly community ponds and tanks). Fish produced in these ponds and tanks are unreported, locally consumed and ignored in the policy domain (Radheyshyam et al., 2013). Fish farming is carried out traditionally under extensive system to meet the requirements of small scale farming households and fitting with the available resources. Such type of fish farming is categorised as "rural aquaculture" (Edwards et al., 2002; Little, 2003; De and Saha, 1999; Radheyshyam et al., 2009, 2013). However, very little is known about the system of farming, management and its implications and these water bodies are under-exploited for scientific fish production due to several constraints (De and Saha, 2006; Radheyshyam et al., 2011a, 2012a). Its potential is quite high and it could play a significant role in improving the nutritional security, income and employment opportunities of the rural poor. Considering the importance of community based aquaculture management in rural areas, several demonstrations are conducted for promoting scientific fish farming (Radheyshyam and Tripathy, 1992; Radheyshyam, 1999; Radheyshyam, et al., 2009, 2012b; De et al., 2012, 2013), however, these attempts lack sustainability. During past several decades, different schemes have been launched by Government and non-Governmental organisations from time to time with the provision of material and technical inputs, to enhance fish production in rural areas by adopting best management practices. A sort of dependency syndrome is created among the farmers as they receive free material inputs from these organisations to continue aquaculture. After withdrawal of material input supports or the seizure of the project, farmers generally discontinue fish culture in community ponds as per recommended package of practices. Probably they find it easier to 
wait for another agency to come and launch a project for demonstrating benefits of scientific fish farming. Therefore, it is worthwhile to change the behaviour of the community fish farmers through motivational drives and technical advices through various means for sustained fish farming utilising available material inputs within their capacity. Keeping this in view, the present investigation was carried out to study the impact of technical advices provided through aquaculture field schools (AFSs) in improving pond management to increase fish production and profitability.

The village community ponds were created for multiple usage and this accounts for around $60 \%$ of the total available ponds and tanks (Radheyshyam et al., 2011a). However, these water bodies are under-exploited for scientific fish culture due to myriad of constraints limiting fish production, even though their potential is quite high. (Radheyshyam et al., 2013). The constraints and status of community fish farming and its economics in rural Odisha has been reported by Radheyshyam (2001), De and Saha (2006), Radheyshyam et al. (2011a), Radheyshyam et al. (2012a) and Radheyshyam et al. (2013). In order to mitigate technical problems, two AFSs were established where community fish farmers and farm women were trained by farmer resource persons of AFSs utilising their fish farm as class room. The project "Community based management for sustainable aquaculture in rural area" was undertaken during 2009-2012 in Khurda and Puri districts of Odisha through provision of only technical advices to fish farmers. Baseline survey was conducted by interviewing 81 randomly selected farmers operating community ponds to understand the status of aquaculture management practices, level of fish production and profitability (Radheyshyam et al., 2013). Various constraints limiting fish production were analysed (Radheyshyam et al., 2011a, 2012a). As part of the project, two AFSs were established during 2009 in the study area in order to promote farmer to farmer extension. At each AFS, technology demonstration, need-based skill training, field days and workshops on community based aquaculture and field visits were organised periodically for those fish farmers and women self help groups (WSHGs) who were involved in community fish farming. Community fish farmers were also trained at ICAR-Central Institute of Freshwater Aquaculture (ICAR-CIFA), Bhubaneswar. Technical advice and follow up action were provided to the farmers as per need. Impact of the approach was studied by collecting data from 31 randomly selected village community ponds (spread over about 36 ha water area) during 2012. Data on pond management, material inputs use, fish production and economic profitability were collected from these selected community ponds at the end of the project. Appropriate statistical analyses (' $\mathrm{t}$ ' test-two samples assuming unequal variances) were carried out to find out the significant differences in productivity level, level of investment and average net return between pre and post-project period.

A comparison of extent of adoption of aquaculture practices was made before and after the project. During pre-project period, only aquatic weeds were removed from $54 \%$ village community ponds, whereas after the project this practice was adopted in $100 \%$ ponds (Table1). Aquatic weed infestation causes nutrient removal (Olah and Sinha, 1984; Radheyshyam and Naik, 1988) from the pond water. It cuts off sunlight penetration during day and depletes oxygen level at night (Radheyshyam et al., 1986). It causes poor production of natural fish food organisms and stress to fish. Low fish production from the village community ponds could be attributed to the cumulative effects of the aforesaid factors (Radheyshyam et al.,

Table 1. Community pond management practices during pre and post-project period. Figures in parenthesis indicate $\%$ of ponds adopting the management practice

\begin{tabular}{|c|c|c|c|}
\hline Parameters & Pre-project & Post-project & Recommended practice \\
\hline Aquatic weed control & $(54)$ & $(100)$ & $(100)$ \\
\hline Weed and predatory fish removal & (36) & $(66)$ & $(100)$ \\
\hline Organic manure application $\left(\mathrm{kg} \mathrm{ha}^{-1} \mathrm{yr}^{-1}\right)$ & 3182 & $6667(74)$ & $10000-15000(100)$ \\
\hline Inorganic fertilizer application $\left(\mathrm{kg} \mathrm{ha}^{-1} \mathrm{yr}^{-1}\right)$ : Urea & $(35)$ & $224(25)$ & $156-225$ \\
\hline SSP & $168(5)$ & $126(13)$ & $200-300$ \\
\hline Lime application $\left(\mathrm{kg} \mathrm{ha}^{-1} \mathrm{yr}^{-1}\right)$ & $153(72)$ & $217(94)$ & $200-500(100)$ \\
\hline Stocking: Fry & (47) & (0) & $(0)$ \\
\hline Fingerling & $(53)$ & (84) & $(100)$ \\
\hline Yearling & $(0)$ & (16) & $(100)$ \\
\hline Stocking rate $\left(\right.$ No. ha $\left.{ }^{-1}\right)$ & 15066 & 8841 & $7000-10000(100)$ \\
\hline GNOC feeding $\left(\mathrm{kg} \mathrm{ha}^{-1} \mathrm{yr}^{-1}\right)$ & $221(30)$ & $351(61)$ & $3000-4000(100)$ \\
\hline Rice bran feeding $\left(\mathrm{kg} \mathrm{ha}^{-1} \mathrm{yr}^{-1}\right.$ & $638(40)$ & $710(84)$ & $3000-4000(100)$ \\
\hline Fish production $\left(\mathrm{kg} \mathrm{ha}^{-1} \mathrm{yr}^{-1}\right)$ & 1081 & 2192 & $4000-5000$ \\
\hline
\end{tabular}


2013). Complete removal of aquatic weeds has positive impact on fish production.

Weed and predatory fishes were eradicated from $36 \%$ of the village community ponds in the pre project period which was improved to $66 \%$ at the end of the project i.e., 30\% additional community fish ponds were made free from weeds and predatory fishes. Predatory fish prey upon the fry and fingerlings of carps and the weed fishes compete with carps for food, space and oxygen (Sinha, 1979; Sinha and Ramchandran, 1985; Kumar, 1992; Jena, 2006). Community ponds which were made free from weed and predatory fishes showed higher fish production (Radheyshyam et al., 2013). In the present investigation, the technical inputs impacted on weed and predatory fish eradication from more community ponds, which in turn resulted in higher fish production.

To increase pond productivity, organic manure was applied in 35\% ponds (@3182 kg ha-1 $\mathrm{yr}^{-1}$ ) along with inorganic fertilizer in 5\% ponds (@168 kg ha-1 $\mathrm{yr}^{-1}$ ) during the pre-project period. This was improved to $74 \%$ ponds with organic manure (@6667 kg ha-1 $\mathrm{yr}^{-1}$ ) and 35\% ponds with inorganic fertilizers (@420 kg ha ${ }^{-1} \mathrm{yr}^{-1}$ ), either in combination or alone. This shows intensification in pond fertilization due to technical inputs for increasing pond productivity. Lime application also increased from 72\% ponds (@153 kg ha-1 $\mathrm{yr}^{-1}$ ) to 94\% ponds (@217 kg ha' $\mathrm{yr}^{-1}$ ), which indicates better pond management due to constant technical guidance provided through AFSs. Radheyshyam et al. (2013) suggested that community ponds should also be treated with raw cow dung and inorganic fertilizers at recommended dose to increase natural fish food organisms so as to increase fish production and net profit.

The village community ponds are generally stocked with carp fry and fingerlings in improper ratios without eradicating aquatic weeds as well as predatory and trash fishes (Radheyshyam et al., 2013). This adversely affects fish production. Fingerlings and/or yearlings were stocked in $53 \%$ of the ponds before the project and it was increased to $100 \%$ after the project (Table 1). Radheyshyam et al. (2013) reported that stocking community ponds with fingerlings and yearlings results in higher fish production than stocking with fry. Average stocking density fell from 13227 seed ha $^{-1}$ to 8841 seed ha $^{-1}$ at the end of the project. Low stocking density was due to adoption of large size fish seed (fingerlings and/or yearlings).

The abundance of fish food organisms in village community ponds may not be enough to meet the nutritional requirement of the stocked fish and hence supplementary feed need to be provided. Radheyshyam et al. (2013) stated that even partial feeding accelerates fish production significantly. In the present investigation, in $30 \%$ ponds fish were fed with groundnut oilcake (GNOC@ $221 \mathrm{~kg} \mathrm{ha}^{-1} \mathrm{yr}^{-1}$ ) and in 40\% ponds with rice bran (@638 kg ha-1 $\mathrm{yr}^{-1}$ ) prior to the project initiation which increased to 61\% ponds (@351 kg ha $\mathrm{kr}^{-1}$ ) and to 84\% ponds (@710 kg ha $\mathrm{yr}^{-1}$ ) respectively at the end of the project (Table 1). This clearly indicates that technical inputs helped to improve quality of feeding in community ponds. However, the feeding was at lower levels than the recommended feeding schedule. Intensification of pond management practices and fish feeding during the project provided better situation for fish growth and production resulting in significantly higher $(p<0.05)$ fish yield (@2192 kg ha-1 $\mathrm{yr}^{-1}$ ) than pre-project period (@) $1081 \mathrm{~kg} \mathrm{ha}^{-1} \mathrm{yr}^{-1}$ ). However, there is further scope to increase fish production through intensification of management practices. Evidently, Radheyshyam et al. (2012b) reported fish production @7650 kg ha-1 $\mathrm{yr}^{-1}$ from 14 community ponds (27.2 ha) in succession fish farming.

Eradication of unwanted fishes using recommended fish poisons, pond fertilizers and fish feed constitute the major share in operational expenditure. Most of the farmers interviewed, reported lack of resources to meet the operational expenses and/or unwillingness to invest in community fish farming. As evident from Table 1, the level of input use by the farmers even after the project period is less than the recommended doses.

Motivational drive, need based technical inputs using various means and follow up actions brought changes in behaviour of the community fish farmers for higher investment towards intensification of pond management, feed and fertilizer application, purchase of fingerlings and yearlings, labour inputs and other miscellaneous expenditure (Table 2). Evidently pre-project investment in community based aquaculture was ₹40146 $\mathrm{ha}^{-1} \mathrm{yr}^{-1}$ which increased significantly $(\mathrm{p}<0.05)$ to ₹87071 ha- $\mathrm{yr}^{-1}$ after the project. Increase in pond rentals, pond preparation, manure and fertilizer application, fish feed, labour charge and other miscellaneous expenditure was to the tune of $92,702,274,511,63,134$ and 504\% respectively indicating intensive use of inputs in the post-project period. Net return also increased to ₹95068 ha $^{-1} \mathrm{yr}^{-1}$ from ₹34057 ha-1 $\mathrm{yr}^{-1}$ (Table 3). Percentage of net return on total expenditure was higher (109\%) during post-project period than during pre-project (85\%). Cost of fish production also increased from ₹37 to ₹40 per kg during the same period.

The results suggest a significant positive impact of the technical inputs on pond management practices, accelerated input use, fish production and net return from the community based aquaculture in rural area. Based on the findings it may be concluded that the novel approach 
Table 2. Operational cost during pre and post- project $\left(₹ \mathrm{ha}^{-1} \mathrm{yr}^{-1}\right)$

\begin{tabular}{lll}
\hline Parameters & Pre-project & Post-project \\
\hline Pond rental & 3599 & 6907 \\
Pond preparation charges & 424 & 3402 \\
Cost of GNOC & 1529 & 9836 \\
Cost of rice bran & 1245 & 7108 \\
Cost of organic manure & 5478 & 3334 \\
Cost of urea/DAP & 0 & 425 \\
SSP cost & 51 & 196 \\
Lime cost & 1153 & 2598 \\
Seed cost & 5591 & 9131 \\
Manpower charges & 16856 & 29483 \\
Miscellaneus expenditure & 1419 & 8576 \\
Total expenditure & 37345 & 80996 \\
Interest on total cost @ 15\% & 2801 & 6075 \\
(for 6 months) & & \\
Grand total expenditure & 40146 & 87071 \\
\hline
\end{tabular}

Table 3. Fish production and its economics

\begin{tabular}{lll}
\hline Parameters & Pre-project & Post-project \\
\hline $\begin{array}{l}\text { Total fish production } \\
\left(\mathrm{kg} \mathrm{ha}^{-1} \mathrm{yr}^{-1}\right)\end{array}$ & 1081 & 2192 \\
$\begin{array}{l}\text { Gross income from fish sale } \\
\left(₹ \mathrm{ha}^{-1} \mathrm{yr}^{-1}\right)\end{array}$ & 74203 & 182139 \\
$\begin{array}{l}\text { Net income }\left(₹ \mathrm{ha}^{-1} \mathrm{yr}^{-1}\right) \\
\begin{array}{l}\text { Percentage net return on } \\
\text { expenditure }\end{array}\end{array}$ & 34057 & 95068 \\
$\begin{array}{l}\text { Profitability index } \\
\text { Cost of fish production }\left(₹ \mathrm{~kg}^{-1}\right)\end{array}$ & 37 & 109 \\
\hline
\end{tabular}

tried by ICAR-CIFA for transferring technologies through AFS has yielded positive results. The approach relied heavily on non-monetary inputs with technical advice and interaction as primary intervention. Sharing of experiences with the lead farmer at the AFS has brought in confidence among them in scientific fish farming. This approach of 'farmer to farmer' extension with no physical input would certainly be sustainable in the long run. It is suggested that AFS be established in each district with the provision of minimum logistics to the lead farmer enabling him to meet the information requirement effectively. The new approach tested through the study confirms that if need based technical guidance is provided; farmers would adopt scientific practices.

\section{Acknowledgements}

The authors wish to express their gratitude to the Director, ICAR-Central Institute of Freshwater Aquaculture (CIFA), Bhubaneswar for providing facilities to conduct the study and to the Head, Aquaculture Production and Environment Division of ICAR-CIFA for his encouragement and support for the study. Authors thank Shri. Tarun Shyam for statistical analysis. The community fish farmers deserve special thanks for their co-operation in the survey.

\section{References}

De, H. K., Saha, G. S. and Radheyshyam. 2013. Aquaculture field school to promote farmer-to-farmer extension. J. Global Commun., 6(2): 77-85.

De, H. K. and Saha, G. S. 1999. Rural aquaculture prospects and potentials. Indian Farming, 49(4): 17.

De, H. K. and Saha, G. S. 2006. Constraints to community based aquaculture. Indian J. Ext. Educ., 42(3\&4): 66-68.

De, H. K., Chattopadhyay, D. N., Radheyshyam, Saha, G. S., Dash, A. K., Pal, S. and Satpati, T. S. 2012. Strengthening the livelihoods of rural women through polyculture of carps in seasonal ponds. Indian J. Fish., 50(3): 137-141.

Edwards, P., Little, D. C. and Demaine, H. 2002. Rural aquaculture, CABI, Wallingford, $358 \mathrm{pp}$.

Jena, J. K. 2006. Carp culture. In: Hand book of fisheries and aquaculture, Indian Council of Agricultural Research, New Delhi, p. 265-282.

Kumar, D. 1992. Fish culture in un-drainable ponds: A manual for extension, FAO Fisheries Technical paper, 325: 239 pp.

Little, D. 2003. Defining peri-urban aquaculture in Asia, PAPUSSA, (Production in Aquatic Peri-Urban Systems in Southeast Asia), EC-Inco DEVICA-2001-10072.

Olah, J. and Sinha, V. R. P. 1984, Principles and methods of monitoring of perennial undrainable pond ecosystems in tropical monsoon lands. Aquacult. Hung., 4: 103-110.

Radheyshyam, 1999. Siula, India - A success story in community based freshwater aquaculture. ICAR-Central Institute of Freshwater Aquaculture, Bhubaneswar, 18 pp.

Radheyshyam, 2001. Community based aquaculture in India strengths, weaknesses, opportunities and threats. NAGA, ICLARM Quart., 24(1\&2): 9-12.

Radheyshyam and Naik, D. R. 1988. Studies on the decomposition pattern of submerged weeds, Hydrilla verticillata and Najas foveolata in a freshwater tropical swamp in Orissa. Proceeding of the National Symposium on past, present and future of Bhopal lakes, p. 105-114.

Radheyshyam and Tripathy, N. K. 1992. Aquaculture as nucleus for integrated rural development - An experience. Fishing Chimes, 12(9): 37-48.

Radheyshyam, De, H. K. and Saha, G. S. 2009. Role of community in production and supply of larger quality fingerlings, Aquac. Asia, 14(1): 16-17.

Radheyshyam, Saha, G. S., Safui, L., Eknath, A. E., Adhikari, S., De, H. K., Barik, N. K. and Chandra, S. 2013. Status and economy of community fish farming in rural Odisha. Indian J. Fish., 60(4): 59-67.

Radheyshyam, Saha, G. S., Barik, N. K., Eknath, A. E, De, H. K., Safui, L., Adhikari, S. and Chandra, S. 2011a. Constraints to fish production in community ponds in Orissa, India. Aquac. Asia, 16(1): 25-30. 
Radheyshyam, Saha, G. S. and De, H. K. 2011b. Aquaculture Field Schools as an extension methodology. Aquac. Asia, 16(3): 20-24.

Radheyshyam, Saha, G. S., Barik, N. K., Eknath, A. E., De, H. K., Safui, L., Adhikari, S. and Chandra, S. 2012a. Limitations in rural aquaculture with particular reference to community ponds in Odisha. In: Pandey, A. K. Gopal Pandey and Hemlata Pant (Eds.), Recent advances in agricultural biotechnology. Society of Biological Sciences and Rural Development, Allahabad. p. 296-316

Radheyshyam, Satapathy, B. B. and Sinha, V. R. P. 1986. Environmental diel cycle during mass fish kills and planktonic collapse in an undrainable rural fish pond. NACA/WP./86/27, July, Bangkok, Thailand, p. 1-8.
Radhey Shyam, Tarun Shyam, Saha, G. S. and Kedarnath, 2012b. Carp fry-fingerling-yearling-food fish production in succession in village community ponds and spawn production in own hatchery, In: Radheyshyam, Saha, G. S. and De, H. K. Aquaculture success stories, ICAR-Central Institute of Freshwater Aquaculture, Kausalyaganga, Bhubaneswar, p. 37-59.

Sinha, V. R. P. 1979. Present status of composite fish culture in India. Central Inland Fisheries Research Institute, Barrrackpore, West Bengal.

Sinha, V. R. P. 1999. Rural aquaculture in India. Rap Publication, FAO of the UN, Bangkok, Thailand, 84 pp.

Sinha, V. R. P. and Ramachandran,V. 1985. Freshwater fish culture. Indian Ccouncil of Agricultural Research, New Delhi, 80 pp. 